Journal of Measurement, Electronic, Communication, and Systems (2016) CT0216 01

www.jmecs.org/vol2

\title{
Fuzzy Logic as A Method of Decision Making in Automatic Watering Plants
}

\author{
T. W. Martha ${ }^{1}$, A. N. Jati ${ }^{1}$, F. Azmi ${ }^{1}$ \\ ${ }^{1}$ School of Electrical Engineering, Telkom University, Bandung, 40287, Indonesia
}

\begin{abstract}
In this era of technology, the use of automatic control systems can provide some benefits in terms of efficiency, accuracy, and safety compared to that of manual workmanship. This study tries to create a control system that can perform automatic plant watering system to help us in watering plants. In this study, weather forecast and weather shield are integrated with microcontroller as to gather weather information in the area around the plants. The information is then compared for decision making in automatic watering. This study is derived from the growing popularity of the hobby to grow plants in community. However, the constraint of time and distance in growing plants becomes one of the problems for people who are busy with their activities so that they do not have time for watering plants.
\end{abstract}

Keywords: Fuzzy logic; Automatic control system; Weather effects; Watering plant;

\section{Introduction}

Using home garden as the medium to grow plants is commonly practiced by the society or even becomes their hobby. However, the constraint of time and distance becomes one of the problems that arises in growing plants. In this era of technology, the use of automatic control system is expected to provide some benefits in terms of efficiency, accuracy, and security compared to that of manual workmanship. The purpose of this research is to create a control system that can perform automatic plant watering to help us when we forget watering plants. The weather forecast and weather shield engine are integrated with a microcontroller to gather weather information in the area around the plant which is then compared using fuzzy logic for decision making in automatic watering.

The application of microcontroller as an automatic control system has in particular been developed on crop irrigation systems. A previous study used a 8051 microcontroller as to perform automatic watering plants that was integrated with moisture sensors to measure soil moisture [1]. Interrupting signal was transferred to the microcontroller to activate sprinklers when moisture was detected below the reference [1]. Soil moisture sensor was also used to consider and conserve water content used for watering [2]. Wireless Sensor Network (WSN) as a distributed device is was also used to collect weather information such as temperature, air pressure, humidity and soil moisture on crop irrigation systems [3]. The obtained data were sent to a centralized control system to perform irrigation [3]. The advantages of using WSN are that it can reduce cables used for communication with media sensor, it is simple and flexible in terms of network, it is reliable in the case of data transfer, it requires low cost equipment, it is easy to control and to monitor, and it can also be used for large data [3][4]. 
Weather may affect how the plants grow. All weather parameters that the climate has may influence one another [5]. Changes in temperature cause evaporation of water and air. Thus, it becomes one of the causes of changes in humidity. In addition, the temperature change also affects air pressure that can cause changes in wind speed and direction. Changes in humidity, wind speed and direction, can potentially lead to rainfall [6]. Figure 1 shows the relationship among climate variables.

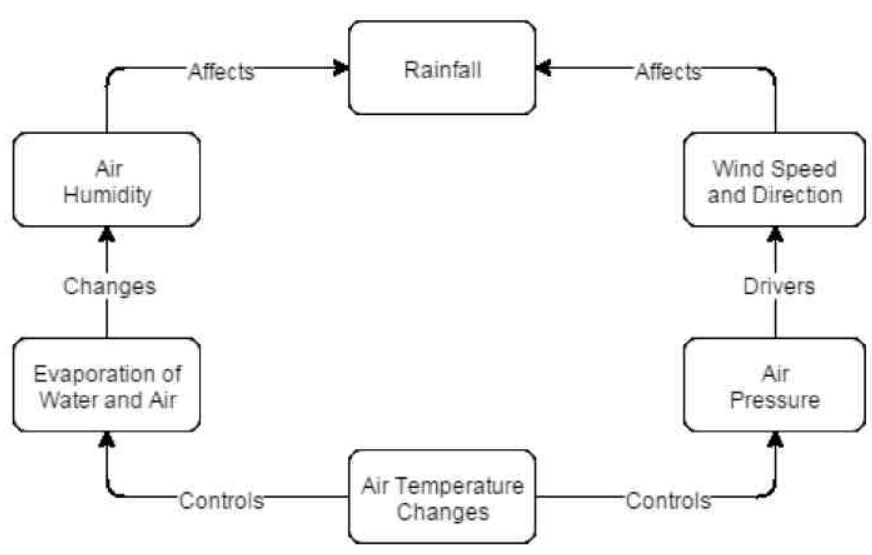

Fig. 1. Correlation of Weather Parameters [6].

The amount of water needed by plants is also indirectly affected by potential rain. It is because that when a heavy rain is potential to fall, the water needed by the crop will be fulfilled by the rain However, if it is not potential to have some rain, the water needed by the plants can be predicted using several parameters such as temperature, humidity, dew point, wind speed, and pressure [5]. The level of humidity is affected by temperature and air pressure. If the temperature increases, the humidity level will also drop. Pressure has also had similar effect to humidity. Thus, temperature is proportional to air pressure yet it is inversely proportional to the humidity [5][6].

The interaction among weather parameters can be made into an artificial intelligence by applying fuzzy logic in control system to support the performance of an automatic irrigation system. It is powered by a learning system where fuzzy logic programming language is easy to be applied to the machine, especially a microcontroller [7]. By integrating WSN on the microcontroller to gather weather information, fuzzy logic can be used for decision making in watering [4]. This technique aims to do the watering according to the needs of plants in order to save water [4]. A previous study in this topic used three sensors, namely the watermark sensor, temperature and humidity sensor, and also leaf wetness sensor [4]. Parameters reviewed were rooting depth, sand texture, water storage capacities of soil, field soil moisture content, leaf wetness, temperature, and humidity [4]. Parameter results were then used as input data in the process of fuzzy logic using Mamdani technique as a the method to get the watering rules (inference) and the centroid technique as a the method to get the value of crisp output (defuzzyfication) [4]. Another study also developed automatic control system using fuzzy logic on evapotranspiration, i.e. the determination of the quantity of water supplied through irrigation [8]. Some weather parameters used as reference were solar radiation, air temperature, air humidity, and wind speed [8]. However, the inference process used Sugeno technique as the method to get the watering rules and weighted average technique as the method to get the value of crisp output on the defuzzification process [8].

The purpose of this study is to design an artificial intelligence in a control system to perform automatic plant watering that implements fuzzy logic. This paper is organized into several parts including Part 1 describes the underlying issues and previous studies related to these problems. Part 2 contains a system design that was made. Part 3 is the explanation of the testing system, the test results and analysis required. The last is Part 4 which describes the conclusion derived from this study.

\section{System Design}

This system is designed so as to use a microcontroller as the control system for a water pump designed for watering plants. It is connected to a server that collects weather information on the location of the plant from a weather forecast engine. In addition, the system is also integrated with a weather shield as the weather sensor around the plant in a short distance. The use of weather shield is helpful if the plants are in the shade or indoors. The weather information obtained from these two sources will be compared and processed using fuzzy logic to perform automatic watering. Figure 2 shows a process flow that occurs. 
Martha et al. / Journal of Measurement, Electronics and Communication Systems (2016) CT0216 01

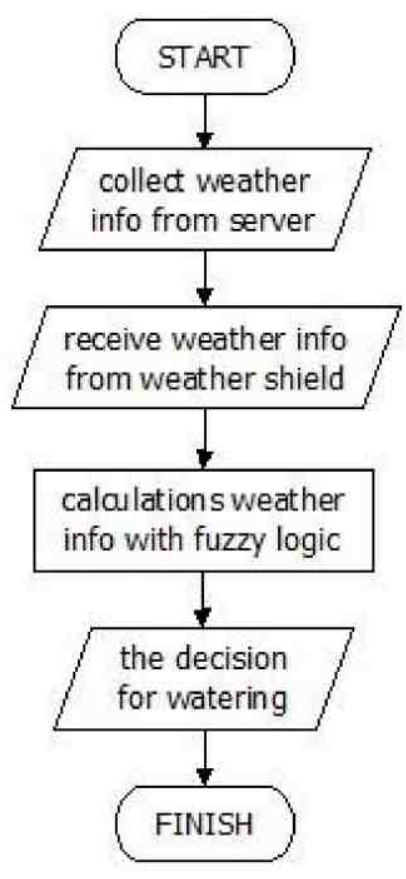

Fig. 2. Flowchart of System.

The design of weather input data obtained from the server and weather shied as well as that of fuzzy logic process using weather input data obtained can be seen in Figure 2.

\subsection{Design of Weather Input Data}

Weather input data is are designed to retrieve weather data around the plant which has been gathered using weather forecasts and weather shield engine that is integrated with a microcontroller. Weather data from both sources then generate several parameters for decision-making processes in automatic watering using fuzzy logic. Parameters taken are temperature, humidity, and air pressure. The following is pseudo-code design for the weather input data.

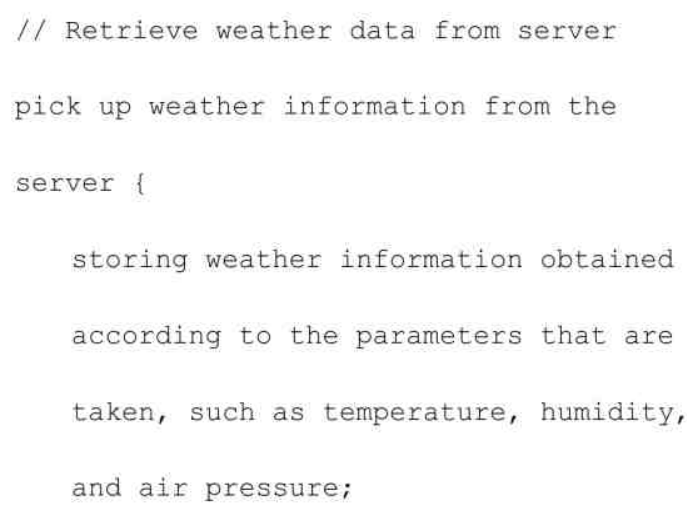

\subsection{Design of Fuzzy Logic}

Weather data that has have been collected from the server and weather shield will be used in the design of fuzzy logic for decision making in automatic watering. In this design there are three processes carried out to obtain the feasibility value of watering including fuzzification, inference and defuzzification. Pseudo code design is then designed for the whole process of fuzzy logic.

1) Design of Fuzzification: aims to get the value of each parameter of weather fuzzy input that has been obtained from the server and weather shield. The result of this fuzzification process will be used in the process of inference to obtain eligibility of the watering rules. Figure 3, 4, and 5 show the membership function used for each parameter, where $\mathrm{T}$ is temperature, $\mathrm{H}$ is the humidity, $\mathrm{P}$ is the air pressure, and $\mu$ is a fuzzy input value.

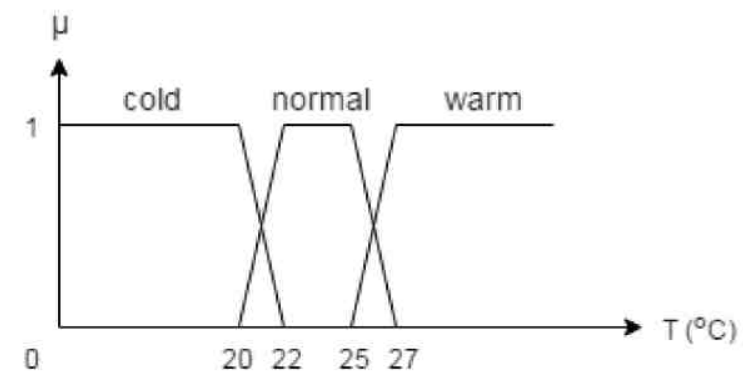

Fig. 3. Membership Function of Temperature.

Based on Figure 3, Eq. (1), Eq. (2), and Eq. (3) can be used to get the value of the fuzzy input of the temperature.

$\mathrm{T}_{\text {cold }}(\mathrm{x})= \begin{cases}1 & , x \leq 20 \\ \frac{22-x}{22-20} & , 20<x<22 \\ 0 & , x \geq 22\end{cases}$ 


$$
\begin{aligned}
& \mathrm{T}_{\text {normal }}(\mathrm{x})= \begin{cases}1 & , 22<x<25 \\
\frac{22-x}{22-20} & , 20<x<22 \\
\frac{27-x}{27-25} & , 25<x<27 \\
0 & , x \leq 20 \text { or } x \geq 27\end{cases} \\
& \mathrm{T}_{\text {warm }}(\mathrm{x})= \begin{cases}\frac{1}{27-x} & , 25 \geq 27 \\
\frac{27-25}{0} & , 25 \leq 25\end{cases}
\end{aligned}
$$

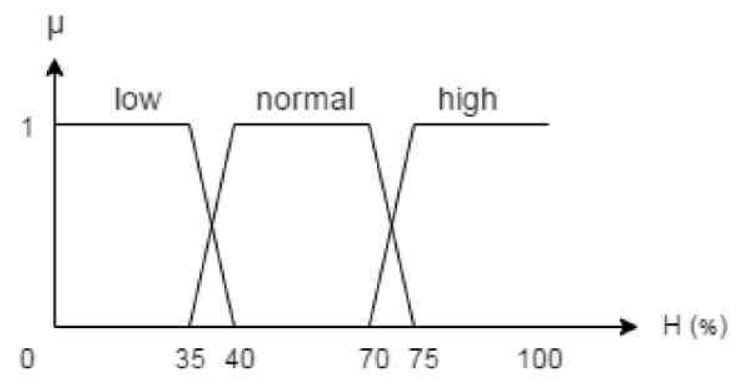

Fig. 4. Membership Function of Humidity.

Based on Figure 4, Eq. (4), Eq. (5), and Eq. (6) can be used to get the value of the fuzzy input of the humidity.

$$
\begin{aligned}
& \mathrm{H}_{\text {low }}(\mathrm{x})= \begin{cases}1 & , x \leq 35 \\
\frac{40-x}{40-35} & , 35<x<40 \\
0 & , x \geq 40\end{cases} \\
& \mathrm{H}_{\text {normal }}(\mathrm{x})= \begin{cases}1 & , 40<x<70 \\
\frac{40-x}{40-35} & , 35<x<40 \\
\frac{75-x}{75-70} & , 70<x<75 \\
0 & , x \leq 35 \text { or } x \geq 75\end{cases} \\
& \mathrm{H}_{\text {high }}(\mathrm{x})= \begin{cases}\frac{1}{75-x} & , 70<x<75 \\
\frac{75-70}{0} & , x \leq 70\end{cases}
\end{aligned}
$$

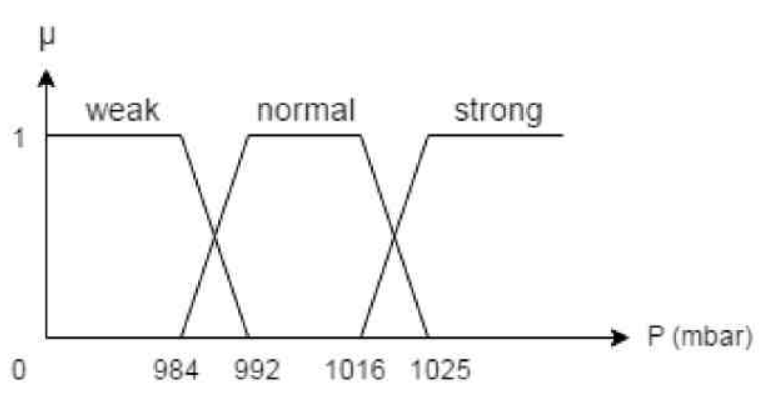

Fig. 5. Membership Function of Air Pressure.

Based on Figure 5, Eq. (7), Eq. (8), and Eq. (9) can be used to get the value of the fuzzy input of the air pressure.

$$
\begin{aligned}
& \mathrm{P}_{\text {weak }}(\mathrm{x})= \begin{cases}1 & , x \leq 984 \\
\frac{992-x}{992-984} & , 984<x<992 \\
0 & , x \geq 992\end{cases} \\
& \mathrm{P}_{\text {normal }}(\mathrm{x})= \begin{cases}\frac{1}{992-984} & , 984<x<992 \\
\frac{1025-x}{1025-1016} & , 1016<x<1025 \\
0 & , x \leq 984 \text { or } x \geq 1025\end{cases} \\
& \mathrm{P}_{\text {strong }}(\mathrm{x})= \begin{cases}\frac{992-x}{1} & , x \geq 1025 \\
\frac{1025-x}{1025-1016} & , 1016<x<1025 \\
0 & , x \leq 1016\end{cases}
\end{aligned}
$$

where each $\mathrm{x}$ is the value of weather parameters (temperature, humidity, and air pressure) obtained from the server and weather shield.

2) Design of Inference: aims to get the fuzzy output value of each fuzzy input value that has been obtained in from fuzzification process. Fuzzy value of this output will be processed to obtain the feasibility of watering rules. This design is similar to the one used in Sugeno models, namely one of the models used for the inference process control system which is suitable for the optimization, adaptive techniques, mathematical analysis, and rapid response [8], [9]. Sugeno linguistic value in the model has only one crisp value. 


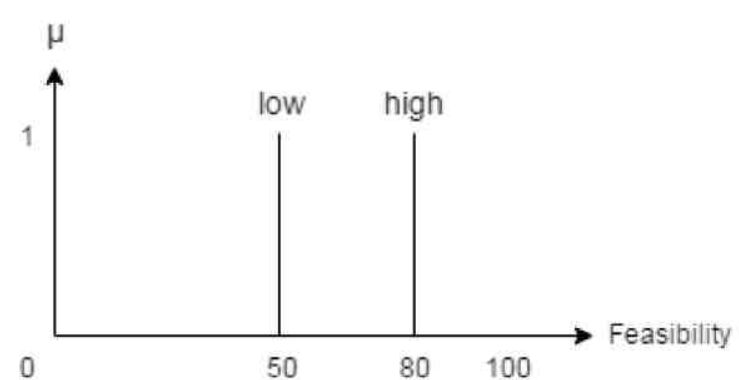

Fig. 6. Membership Function of Feasibility Value.

Based on Figure 6, the combination of the three parameters used generates 27 fuzzy rules that will be used to determine the feasibility of automatic watering. Feasibility value obtained will be used as the reference for the duration of watering.

3) Design of Defuzzification: aims to get the output value of crisp value of feasibility obtained from the interference process. In this design, Weighted Average method is used to obtain the output value as in the following Eq. (10).

$$
y^{*}=\sum \frac{\mu(y) \times y}{\mu(y)}
$$

where $y^{*}$ is the value of defuzzification, $\mu(y)$ is a fuzzy value for each feasibility value, and $y$ is the value of feasibility as the linguistic value. Results of defuzzification process are used as reference for automatic watering.

\section{4) Design of Pseudo Code.}

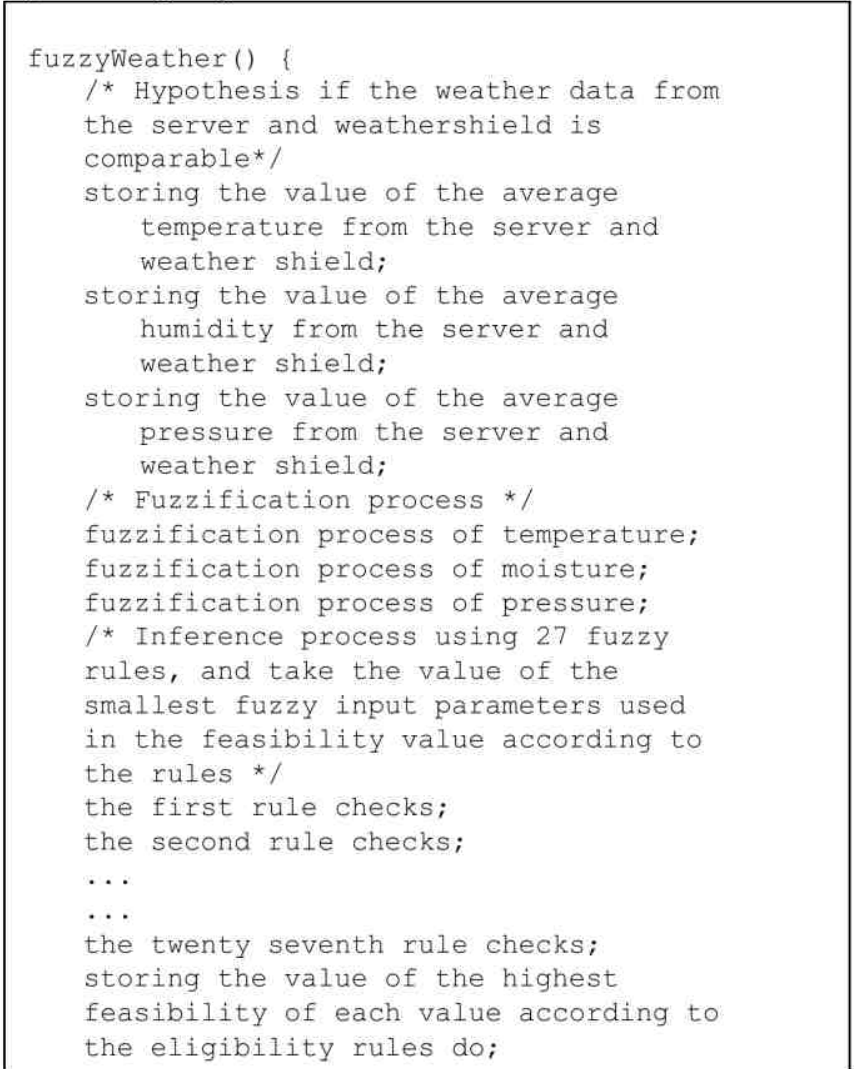

\section{Testing and Analysing}

Tests conducted in this study discusses the decision making process of automatic watering using fuzzy logic. The purpose of testing with fuzzy logic decision making is knowing the obtained feasibility value of weather parameters which are retrieved from the server and weather shield to perform automatic watering. The test is performed every 6 hours for 3 days. The data shown in Table 1 are the result of weather measurements performed on both sources.

Table 1. Weather Measurement Results

\begin{tabular}{|c|c|c|c|c|c|c|c|}
\hline \multirow{2}{*}{ Day } & \multirow{2}{*}{ Hour } & \multicolumn{3}{|c|}{ Weather from Server } & \multicolumn{3}{|c|}{$\begin{array}{c}\text { Weather from } \\
\text { Weather Shield }\end{array}$} \\
\hline & & $\begin{array}{c}\mathrm{T} \\
\left({ }^{\circ} \mathrm{C}\right)\end{array}$ & $\begin{array}{c}\mathrm{P} \\
\text { (mbar) }\end{array}$ & $\begin{array}{c}\mathrm{H} \\
(\%)\end{array}$ & $\begin{array}{c}\mathrm{T} \\
\left({ }^{\circ} \mathrm{C}\right)\end{array}$ & $\begin{array}{c}\mathrm{P} \\
\text { (mbar) }\end{array}$ & $\begin{array}{c}\mathrm{H} \\
(\%)\end{array}$ \\
\hline \multirow{4}{*}{1} & 0 & 23,95 & 916,46 & 83 & 22,93 & 941,58 & 61 \\
\hline & 6 & 18,23 & 918,56 & 96 & 27,88 & 937,55 & 67 \\
\hline & 12 & 18,63 & 917,90 & 96 & 32,21 & 941,43 & 43 \\
\hline & 18 & 23,60 & 919,47 & 83 & 32,02 & 940,53 & 40 \\
\hline \multirow{4}{*}{2} & 0 & 22,33 & 917,01 & 88 & 34,15 & 940,90 & 37 \\
\hline & 6 & 19,00 & 919,48 & 97 & 26,66 & 938,16 & 52 \\
\hline & 12 & 18,54 & 917,98 & 100 & 24,10 & 942,22 & 62 \\
\hline & 18 & 26,06 & 919,17 & 75 & 23,31 & 940,39 & 64 \\
\hline \multirow{4}{*}{3} & 0 & 24,29 & 916,54 & 80 & 24,25 & 940,49 & 55 \\
\hline & 6 & 20,86 & 919,35 & 96 & 26,39 & 937,44 & 52 \\
\hline & 12 & 19,44 & 917,56 & 99 & 24,42 & 941,45 & 63 \\
\hline & 18 & 25,82 & 919,07 & 78 & 24,64 & 940,29 & 61 \\
\hline \multicolumn{2}{|c|}{ Average } & 21,73 & 918,21 & 89,25 & 26,91 & 940,20 & 54,75 \\
\hline
\end{tabular}

Based on table 1, it can be seen there are some deviation or difference that arises between the weather data from the server and the ones from weather shield. The average error between the two sources can be determined using the Mean Absolute Error (MAE) model. Accordingly, the accuracy of weather data obtained prior to the process of fuzzy logic for decision making in automatic watering can also be determined.

$M A E=\sum_{i=1}^{N} \frac{\left|x_{i}-y_{i}\right|}{N}$

where $x_{i}$ is the server weather parameters (temperature, humidity, and air pressure), $y_{i}$ is a weather shield weather parameters (temperature, humidity, and air pressure), and $\mathrm{N}$ is the number of trials. 
Martha et al. / Journal of Measurement, Electronics and Communication Systems (2016) CT0216 01

Table 2. Measurement of Error

\begin{tabular}{|c|c|c|c|c|}
\hline \multirow{2}{*}{ Day } & \multirow{2}{*}{ Hour } & \multicolumn{3}{|c|}{ Error } \\
\hline & & $T\left({ }^{\circ} \mathrm{C}\right)$ & $P$ (mbar) & $H(\%)$ \\
\hline \multirow{4}{*}{1} & 0 & 1,02 & 25,12 & 22 \\
\hline & 6 & 9,65 & 18,99 & 29 \\
\hline & 12 & 13,58 & 23,53 & 53 \\
\hline & 18 & 8,42 & 21,06 & 43 \\
\hline \multirow{4}{*}{2} & 0 & 11,82 & 23,89 & 51 \\
\hline & 6 & 7,66 & 18,68 & 45 \\
\hline & 12 & 5,56 & 24,24 & 38 \\
\hline & 18 & 2,75 & 21,22 & 11 \\
\hline \multirow{4}{*}{3} & 0 & 0,04 & 23,95 & 25 \\
\hline & 6 & 5,53 & 18,09 & 44 \\
\hline & 12 & 4,98 & 23,89 & 36 \\
\hline & 18 & 1,18 & 21,22 & 17 \\
\hline \multicolumn{2}{|c|}{ MAE } & 6,02 & 21,99 & 34,50 \\
\hline
\end{tabular}

From table 2, it can be analyzed that there are some error or difference between the weather data from the server and the ones from weather shield influenced by the temperature of the microcontroller. This is because the performance of microprocessors on board causes the temperature rises and affects the measurement of the weather shield. Rising temperatures also affect the humidity obtained since the relationship between temperature and humidity are inversely proportional. Based on this analysis, the level of weather data from the weather shield can then be measured. By comparing the average error and average weather data from the server, the level of accuracy in weather shield can be measured using Eq. (12).

$$
\text { Accuracy }=\left(1-\frac{M A E}{X}\right) \times 100 \%
$$

where $X$ is any server weather parameters (temperature, humidity, or air pressure) compared with the results of MAE.
Table 3. Measurement Accuracy of Each Parameters

\begin{tabular}{|c|c|c|c|c|c|}
\hline \multicolumn{3}{|c|}{ MAE } & \multicolumn{3}{c|}{ Accuracy (\%) } \\
\hline T ( $\left.{ }^{\circ} \mathrm{C}\right)$ & P (mbar) & H (\%) & T & P & H \\
\hline 6,02 & 21,99 & 34,50 & 72,2953 & 97,6051 & 61,3445 \\
\hline
\end{tabular}

Based on the level of accuracy obtained in table 3 , there should be sharing of weather parameters by a certain percentage so that the input data on fuzzy logic are in accordance with the condition around the plants. In this research, the division performed was $80 \%$ for the temperature of the server, $20 \%$ for the temperature of the weather shield, $70 \%$ for the humidity of the server, $30 \%$ for the humidity of the weather shield, and the average for the air pressure from the server and weather shield. Table 4 shows the results of the feasibility value of fuzzy logic process for automatically watering plants after the division at each weather parameter.

Table 4. Values of Feasibility Watering Using Fuzzy Logic

\begin{tabular}{|c|c|c|}
\hline Day & Hour & $\begin{array}{c}\text { Values of Feasibility } \\
\text { Watering }\end{array}$ \\
\hline \multirow{4}{*}{1} & 0 & 50 \\
\hline & 6 & 50 \\
\hline & 12 & 50 \\
\hline & 18 & 80 \\
\hline \multirow{4}{*}{2} & 0 & 62 \\
\hline & 6 & 50 \\
\hline & 12 & 50 \\
\hline & 18 & 66,67 \\
\hline \multirow{4}{*}{3} & 0 & 62 \\
\hline & 6 & 50 \\
\hline & 12 & 50 \\
\hline & 18 & 63,33 \\
\hline \multicolumn{2}{|c|}{ Average } & 57,00 \\
\hline
\end{tabular}

Division can minimize the possibility of excessive watering due to the obtained feasibility value in automatic watering that does not comply with the condition around the plants.

\section{Conclusions}

From the research that has been done, fuzzy logic in automatic control systems as a method for 
watering plants can be applied by using weather data such as temperature, air pressure, and humidity as a reference for watering. However, the effect of temperature on the microprocessor causes the weather to the weather shield measurement is less accurate. By analyzing the results of the measurement accuracy, the process can be proceeded to the distribution of weather parameters by a certain percentage. It is to minimize the possibility of excessive watering due to the obtained feasibility value in automatic watering that does not comply with the condition around the plants. From these results, fuzzy logic techniques can further be developed to include some additional parameters to improve the accuracy of weather measurements around the plant, such as the measurement of soil moisture, water discharge given in each watering, and water evaporation. So it can be estimated how long it takes to do the watering of plants by considering the watering conducted previously.

\section{Nomenclature}

$\begin{array}{ll}\text { WSN } & : \text { Wireless Sensor Network } \\ \mu & : \text { Fuzzy Value } \\ \mathrm{T} & : \text { Temperature } \\ \mathrm{P} & : \text { Air Pressure } \\ \mathrm{H} & : \text { Humidity } \\ y^{*} & : \text { Defuzzification Value } \\ \text { MAE } & : \text { Mean Absolute Error }\end{array}$

\section{Reference}

[1] Venkata N. R. Gunturi. Micro Controller Based Automatic Plant Irrigation System. International Journal of Advancements in Research \& Technology. 2 (4) (2013). 194-198.

[2] J. Dhiman, S. Singh, and S. Dhiman. Utilization of Irrigation Water Using Microcontroller. Automatic Control and Information Sciences. 1 (1) (2013). 1-5.

[3] R. Atta, T. Boutraa, and A. Akhkha. Smart Irrigation System for Wheat in Saudi Arabia Using Wireless Sensors Network Technology. International Journal of Water Resources and Arid Environments. 1 (6) (2011). 478-482.
[4] P. Patil, U. Kulkarni, B.L. Desai, V.I. Benagi, and V.B. Naragund. FUZZY LOGIC BASED IRRIGATION CONTROL SYSTEM USING WIRELESS SENSOR NETWORK FOR PRECISION AGRICULTURE. Agro-Informatics and Precision Agriculture. India (2012).

[5] Givoni B. Climate and Architecture. Van Nostrand Reinhold Company. London (1976).

[6] Sheeba Valsson and Alka Bharat. Impact of Air Temperature on Relative Humidity. ARHITECHTURE - Time Space \& People (2011). 38-41.

[7] L.A. Zadeh. Fuzzy Sets. Information and Control. Department of Electrical Engineering and Electronics Research Laboratory, University of California. 8 (1965). 338-353.

[8] A.K. Mousa, M. S. Croock, and M.N. Abdullah. Fuzzy based Decision Support Model for Irrigation System Management. International Journal of Computer Applications. 104 (9) (2014). 14-20.

[9] Lee, Kwang H.. 2005. First Course on Fuzzy Theory and Applications. Berlin: Springer. 